\title{
Correction to: Glucagon-Like Peptide-1 Receptor Agonists in Type 2 Diabetes: Their Use and Differential Features
}

\author{
Katherine A. Lyseng-Williamson ${ }^{1}$ (D)
}

Published online: 17 August 2019

(c) Springer Nature Switzerland AG 2019

\section{Correction to: Clinical Drug Investigation (2019) 39:805-819 https://doi.org/10.1007/ s40261-019-00826-0}

The original version of this article unfortunately contained some mistakes. The corrected details are provided below:

Page 805: The title of the article, which previously read:

"Glucagon-Like Peptide-1 Receptor Analogues in Type 2 Diabetes: Their Use and Differential Features"

should read:

"Glucagon-Like Peptide-1 Receptor Agonists in Type 2 Diabetes: Their Use and Differential Features"

Running header, which previously read:

"Glucagon-Like Peptide-1 Receptor Analogues in Type 2 Diabetes"

should read:

"Glucagon-Like Peptide-1 Receptor Agonists in Type 2 Diabetes"

Page 805, Abstract: The beginning of the first sentence, which previously read:

"Glucagon-like peptide-1 receptor analogues/agonists"

The original article can be found online at https://doi.org/10.1007/ s40261-019-00826-0.

Katherine A. Lyseng-Williamson

DEcorrespondence@ springer.com

Springer Nature, Private Bag 65901, Mairangi Bay, Auckland 0754, New Zealand should read:

"Glucagon-like peptide-1 receptor agonists"

Page 805, Section 1, para 2, end of the second sentence, which previously read:

"thereby providing the rationale for developing GLP-1 receptor analogues/agonists (GLP-1RAs) to treat T2D [3]."

Should read:

"thereby providing the rationale for developing GLP-1 receptor agonists (GLP-1RAs) to treat T2D [3]."

Page 811, Section 4, para 2, end of the first sentence, which previously read:

"some other glucose-lowering drugs (most frequently semaglutide vs sitagliptin or insulin glargine [28-32]) [Table 3]"

Should read:

"some other glucose-lowering drugs (most frequently semaglutide vs sitagliptin or insulin glargine [28-32]) [Table 3]."

Page 817, first column, last para, first sentence, which previously read:

"GLP-1RAs must be administered subcutaneously, which is disadvantage relative to the convenient oral administration of most other classes of glucose-lowering drugs."

Should read:

"GLP-1RAs must be administered subcutaneously, which is a disadvantage relative to the convenient oral administration of most other classes of glucose-lowering drugs." 
Captions of Table 1 (page 807), Table 2 (page 808), Table 3 (page 812), Table 4 (page 814), Table 5 (page 815) and Table 6 (page 816): The part of the table caption, which previously read:

"glucagon-like peptide-1 receptor analogues"

should read:

"glucagon-like peptide-1 receptor agonists"
The following section was inadvertently omitted:

Acknowledgements The author thanks Prof. John Wilding, Obesity \& Endocrinology Research, Institute of Ageing \& Chronic Disease, University of Liverpool, Liverpool, UK for his assistance in preparing this review.

The original article has been corrected. 